\title{
Substitution of the premembrane and envelope protein genes of Modoc virus with the homologous sequences of West Nile virus generates a chimeric virus that replicates in vertebrate but not mosquito cells
}

\author{
Rungrat Saiyasombat ${ }^{1 \dagger}$, Jimena Carrillo-Tripp ${ }^{2 \dagger}$, Wyatt Allen Miller ${ }^{2}$, Peter J Bredenbeek ${ }^{3}$ and Bradley J Blitvich ${ }^{1 *}$
}

\begin{abstract}
Background: Most known flaviviruses, including West Nile virus (WNV), are maintained in natural transmission cycles between hematophagous arthropods and vertebrate hosts. Other flaviviruses such as Modoc virus (MODV) and Culex flavivirus (CXFV) have host ranges restricted to vertebrates and insects, respectively. The genetic elements that modulate the differential host ranges and transmission cycles of these viruses have not been identified.

Methods: Fusion polymerase chain reaction (PCR) was used to replace the capsid (C), premembrane (prM) and envelope (E) genes and the prM-E genes of a full-length MODV infectious CDNA clone with the corresponding regions of WNV and CXFV. Fusion products were directly transfected into baby hamster kidney-derived cells that stably express T7 RNA polymerase. At 4 days post-transfection, aliquots of each supernatant were inoculated onto vertebrate (BHK-21 and Vero) and mosquito (C6/36) cells which were then assayed for evidence of viral infection by reverse transcription-PCR, Western blot and plaque assay.

Results: Chimeric virus was recovered in cells transfected with the fusion product containing the prM-E genes of WNV. The virus could infect vertebrate but not mosquito cells. The in vitro replication kinetics and yields of the chimeric virus were similar to MODV but the chimeric virus produced larger plaques. Chimeric virus was not recovered in cells transfected with any of the other fusion products.

Conclusions: Our data indicate that genetic elements outside of the prM-E gene region of MODV condition its vertebrate-specific phenotype.
\end{abstract}

Keywords: Modoc virus, West Nile virus, Culex flavivirus, Chimeric flavivirus, Fusion PCR

\section{Introduction}

All viruses in the genus Flavivirus (family Flaviviridae) possess a single-stranded, positive-sense RNA genome of approximately $11 \mathrm{~kb}$ [1]. The genome contains a single open reading frame (ORF) flanked by 5 ' and 3 ' untranslated regions (UTRs) of $\sim 100$ and 400-700 nt, respectively [2]. The 5' end of the genome contains a type I cap structure

\footnotetext{
* Correspondence: blitvich@iastate.edu

${ }^{\dagger}$ Equal contributors

'Department of Veterinary Microbiology and Preventive Medicine College of Veterinary Medicine, lowa State University, Ames, lowa, USA Full list of author information is available at the end of the article
}

and the 3' end is non-polyadenylated. The ORF encodes a single polyprotein that is co- and post-translationally cleaved to generate three structural proteins, designated the capsid $(\mathrm{C})$, premembrane/membrane $(\mathrm{prM} / \mathrm{M})$ and envelope $(\mathrm{E})$ proteins, and at least seven non-structural (NS) proteins in the gene order: $5^{\prime}-\mathrm{C}-\mathrm{prM}(\mathrm{M})-\mathrm{E}-\mathrm{NS} 1-$ NS2A-NS2B-NS3-NS4A-NS4B-NS5-3' [1,3]. Cleavage events are mediated by a combination of endoplasmic reticulum signalases, furin and the viral trypsin-like serine protease $[1,4,5]$.

The flavivirus genome is packaged in an icosahedral nucleocapsid with multiple copies of the $\mathrm{C}$ protein [1].

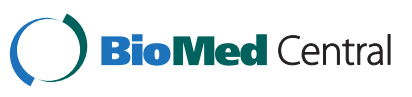

(C) 2014 Saiyasombat et al.; licensee BioMed Central Ltd. This is an Open Access article distributed under the terms of the Creative Commons Attribution License (http://creativecommons.org/licenses/by/4.0), which permits unrestricted use, distribution, and reproduction in any medium, provided the original work is properly credited. The Creative Commons Public Domain Dedication waiver (http://creativecommons.org/publicdomain/zero/1.0/) applies to the data made available in this article, unless otherwise stated. 
The nucleocapsid is surrounded by a lipid envelope, acquired from the host cell, in which the $\operatorname{prM}(\mathrm{M})$ and $\mathrm{E}$ proteins are embedded. The $\mathrm{E}$ protein is required for receptor binding, host membrane fusion and viral assembly, while the prM protein protects the $E$ protein from undergoing an irreversible conformational change as the virion is secreted through acidified sorting compartments [6-9]. RNA replication occurs in the cytoplasm in close association with the rough endoplasmic reticulum and requires the participation of several NS proteins including the viral helicase and protease (NS3), viral protease cofactor (NS2B) and RNA-dependent RNA polymerase and methyltransferase (NS5) [4,10,11].

Flaviviruses can be divided into three distinct groups based upon their mode of transmission [12,13]. The first group is comprised of viruses that are transmitted horizontally between hematophagous arthropods and vertebrate hosts. This group can be further divided into mosquito-borne and tick-borne viruses. Examples of mosquito-borne flaviviruses include West Nile virus (WNV), dengue virus (DENV), yellow fever virus (YFV) and Japanese encephalitis virus (JEV), all of which are human pathogens of global concern [14]. Tick-borne flaviviruses associated with serious human disease include tick-borne encephalitis virus (TBEV), Langat virus (LGTV) and Powassan virus. Flaviviruses in the second group have no known arthropod vector (NKV) and are considered to be vertebrate-specific. NKV flaviviruses have been isolated exclusively from bats and rodents, and examples include Modoc virus (MODV) and Rio Bravo virus [15,16]. The mechanism(s) by which NKV flaviviruses are maintained in nature is poorly defined but it has been suggested that they are transmitted between hosts by nasal and/or oral contact [17-19]. The final group is comprised of insect-specific flaviviruses (ISFs). These viruses are assumed to be insectspecific because they have been isolated from mosquitoes but do not replicate in mice or any vertebrate cell lines that have been tested. More than 20 ISFs have been discovered including Culex flavivirus ( $\mathrm{CxFV}$ ), cell fusing agent virus and Kamiti River virus [20-23]. Recent data indicate that ISFs are maintained in nature by transovarial transmission [24]. It is not known whether ISFs and NKV flaviviruses were originally arthropod-vertebrate flaviviruses that lost the ability to replicate in one host or if they are progenitor viruses from which the arthropod/vertebrate flaviviruses evolved, although the latter theory is favored [25,26].

The evolutionary processes and underlying genetic basis for the differential host ranges and transmission cycles of flaviviruses have not been identified. Thus, the overall goal of this study is to characterize the in vitro host ranges of chimeric viruses constructed using representative viruses from the vertebrate-specific, insect-specific and arthropod/vertebrate flavivirus groups (MODV, CxFV and WNV, respectively) in order to increase our knowledge of the genetic elements that condition the vastly different host ranges and transmissibilities of these viruses.

\section{Materials and methods \\ Cell lines}

BSR-T7/5 cells, which are baby hamster kidney-derived cells that constitutively express T7 RNA polymerase [27], were kindly provided by Cathy Miller (Iowa State University). Baby hamster kidney (BHK-21), African Green Monkey kidney (Vero) and Aedes albopictus (C6/36) cells were obtained from the American Type Culture Collection (Manassas, VA). BSR-T7/5 and BHK-21 cells were cultured in minimum essential medium (Invitrogen, Carlsbad, CA), Vero cells were cultured in Dulbecco's modified Eagle medium (Invitrogen) and C6/36 cells were cultured in Liebovitz L15 medium (Invitrogen). All media was supplemented with $10 \%$ fetal bovine serum (FBS), 2 $\mathrm{mM}$ L-glutamine, 100 units $/ \mathrm{ml}$ penicillin and $100 \mu \mathrm{g} / \mathrm{ml}$ streptomycin. Mammalian cells were cultured at $37^{\circ} \mathrm{C}$ with $5 \% \mathrm{CO}_{2}$ whereas $\mathrm{C} 6 / 36$ cells were cultured at $28^{\circ} \mathrm{C}$.

\section{Viruses}

pACNR-FLMODV, which contains full-length cDNA of MODV (strain M544) downstream of a T7 Ф2.5 promoter (Peter J. Bredenbeek, unpublished data), was used as template for fusion PCR reactions. The plasmid was also used to amplify the full-length product needed to generate MODV. WNV (strain NY99-flamingo382-99) was kindly provided by Aaron Brault (Centers for Disease Control and Prevention). CxFV (strain Iowa07) was originally isolated from Culex pipiens in Iowa in 2007 [28]. cDNAs were generated from WNV and CxFV RNA and used as template for fusion PCR reactions as described below.

\section{Construction of chimeric cDNAs}

Four full-length chimeric flavivirus fusion products, designated fpMODV-WNV(C-prM-E), fpMODV-WNV (prM-E), fpMODV-CxFV(C-prM-E) and fpMODV-CxFV (prM-E), were generated by replacing the C-prM-E and prM-E genes of MODV with the homologous genes of WNV and CxFV. Four conventional PCRs and three fusion-PCRs were required to generate each full-length fusion product (Table 1). The process was facilitated by chimeric primers (half MODV sequence and half heterologous virus sequence) that worked as linkers to fuse the intermediate reaction products and subsequently assemble the final chimeras. The strategy used to construct fpMODV-WNV(prM-E) is depicted in Figure 1 and described below as an example of the chimeric viral cDNA construction process. In the first reaction, a 523 bp product (designated MW1) was amplified by PCR using pACNR-FLMODV as template, a forward primer (M-F1; see Tables 1 and 2) specific to the vector sequence 
Table 1 PCR products generated during the construction of full-length flavivirus chimeric DNAs

\begin{tabular}{|c|c|c|c|c|}
\hline \multirow{2}{*}{$\begin{array}{l}\text { Reaction } \\
\text { no. }\end{array}$} & \multirow{2}{*}{$\begin{array}{c}\text { Reaction } \\
\text { type }\end{array}$} & \multirow{2}{*}{$\begin{array}{c}\text { Primers } \\
\text { (forward, reverse) }\end{array}$} & \multicolumn{2}{|c|}{ PCR product } \\
\hline & & & Name & $\overline{\text { Size (bp) }}$ \\
\hline $1 a$ & PCR & M-F1, MW-R1 & $M W 1^{\prime}$ & 191 \\
\hline $1 b$ & & M-F1, MC-R1 & $M C 1^{\prime}$ & 194 \\
\hline $1 c$ & & M-F1, MWi-R1 & MW1 & 523 \\
\hline $1 d$ & & M-F1, MCi-R1 & MC1 & 521 \\
\hline $2 \mathrm{a}$ & RT-PCR & MW-F2, MW-R2 & MW2' & 2,415 \\
\hline $2 b$ & & MC-F2, MC-R2 & MC2' & 2,167 \\
\hline $2 c$ & & MWi-F2, MWR2 & MW2 & 2,066 \\
\hline $2 d$ & & MCi-F2, MCR2 & MC2 & 1,777 \\
\hline $3 a, c$ & PCR & MW-F3, M-R3 & MW3 & 2,575 \\
\hline $3 b, d$ & & MC-F3, M-R3 & MC3 & 2,580 \\
\hline $4 a-d$ & PCR & M-F4, M-R10600 & M4 & 6,227 \\
\hline $5 a$ & Fusion-PCR & $M-F 1, M W-R 2$ & MW5' & 2,563 \\
\hline $5 b$ & & M-F1, MC-R2 & MC5' & 2,320 \\
\hline $5 c$ & & M-F1, MW-R2 & MW5 & 2,542 \\
\hline $5 d$ & & $M-F 1, M C-R 2$ & MC5 & 2,251 \\
\hline $6 a$ & Fusion-PCR & $M-F 1, M-R 3$ & MW6' & 5,100 \\
\hline $6 b$ & & $M-F 1, M-R 3$ & MC6' & 4,854 \\
\hline $6 c$ & & $M-F 1, M-R 3$ & MW6 & 5,079 \\
\hline $6 d$ & & $M-F 1, M-R 3$ & MC6 & 4,785 \\
\hline $7 a$ & Fusion-PCR & T7MOD-F, M-R10600 & fpMODV-WNV(C-prM-E) & 10,730 \\
\hline $7 b$ & & T7MOD-F, M-R10600 & fpMODV-WNV(prM-E) & 10,708 \\
\hline $7 c$ & & T7MOD-F, M-R10600 & fpMODV-CxFV(C-prM-E) & 10,484 \\
\hline $7 d$ & & T7MOD-F, M-R10600 & fpMODV-CxFV(prM-E) & 10,415 \\
\hline
\end{tabular}

Reactions ending with $a, b, c$ and $d$ were used to generate fpMODV-WNV(C-prM-E), fpMODV-CXFV(C-prM-E), fpMODV-WNV(prM-E) and fpMODV-CxFV(prM-E), respectively.

upstream of the MODV 5'UTR and a chimeric reverse primer (MWi-R1) specific to the distal 3' and 5' ends of the MODV C and WNV prM genes, respectively. In the second reaction, a 2066 bp product (MW2) that contains the entire prM-E genes of WNV was amplified by RT-PCR using total RNA extracted from WNV-infected C6/36 cells as template, a forward chimeric primer (MWi-F2) specific to the sequences at the distal 3' and 5' ends of the MODV C and WNV prM genes, respectively and a reverse chimeric primer (MW-R2) specific to the sequences at the distal 3' and 5' ends of the WNV E and MODV NS1 genes, respectively. In the third reaction, a 2575 bp product (MW3) that contains the entire NS1-NS2A-NS2B genes and part of the NS3 gene of MODV was amplified by PCR using pACNR-FLMODV as template, a forward chimeric primer (MW-F3) specific to the WNV E and MODV NS1 genes and a reverse primer (M-R3) specific to an internal region of the MODV NS3 gene. In reaction four, the remainder of the NS3 gene and the entire NS4A-NS4B-NS5-3'UTR region of MODV was amplified by PCR using pACNR-FLMODV as template and MODV-specific forward and reverse primers (M-F4 and M-R10600, respectively) to give a $6227 \mathrm{bp}$ product (M4). Reaction 5 was a fusion-PCR in which MW1 and MW2 were used as templates and M-F1 and MW-R2 as primers for the generation of a 2542 bp product designated MW5. Reaction 6 was another fusion-PCR in which MW3 and MW5 were used as templates and M-F1 and M-R3 as primers for the generation of a $5079 \mathrm{bp}$ product designated MW6. In the final reaction, a full-length 10,708 bp chimeric fusion product designated fpMODV-WNV(prM-E) was generated by fusion-PCR using M4 and MW6 as templates and T7-MOD-F and M-R10600 as forward and reverse primers, respectively. The 5' end of T7-MOD-F contains the T7 promoter sequence. A similar strategy was adopted for the construction of fpMODV-WNV(C-prM-E), fpMODV-CxFV(C-prM-E) and fpMODV-CxFV(prM-E) with the primers used in these experiments and the sizes of the resulting amplification products denoted in Tables 1 and 2. Full-length MODV was also amplified in a single PCR using pACNR-FLMODV as template, T7-MOD-F as the forward primer and M-R10600 as the reverse primer 

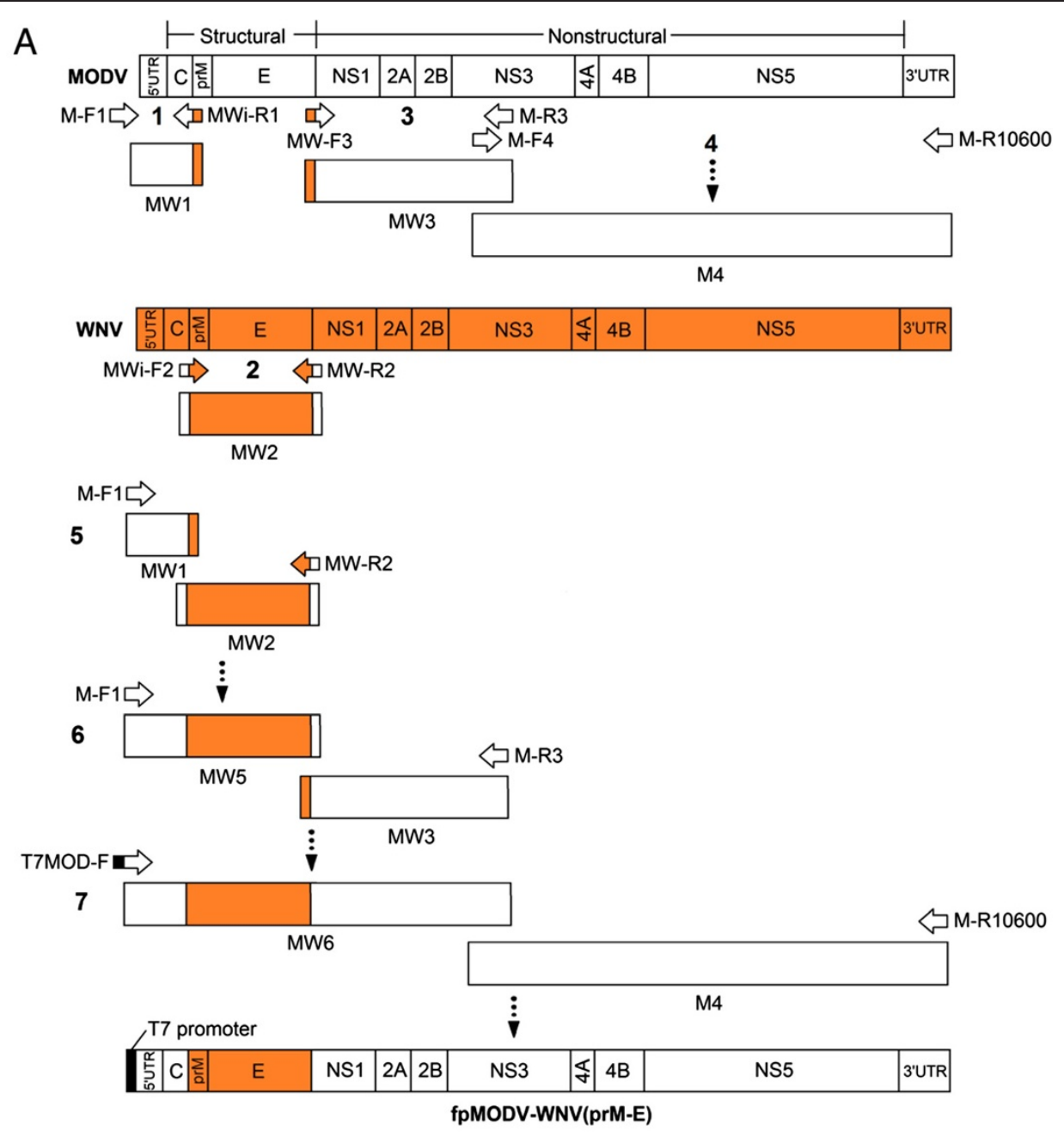

B

\begin{tabular}{|c|c|c|c|c|c|c|c|c|c|}
\hline \multicolumn{10}{|c|}{ T7 promoter } \\
\hline 离 & $E$ & NS1 & $2 \mathrm{~A}$ & $2 B$ & NS3 & $\varangle$ & $4 \mathrm{~B}$ & NS5 & $3^{3} \mathrm{UTR}$ \\
\hline
\end{tabular}

\begin{tabular}{|c|c|c|c|c|c|c|c|c|}
\hline \multicolumn{9}{|c|}{ T7 promoter } \\
\hline \begin{tabular}{|l|l|l|}
\multirow{2}{*}{} & $\mathrm{C}$ & $\bar{\Sigma}$ \\
\end{tabular} & $E$ & NS1 & $2 \mathrm{~A}$ & $2 B$ & NS3 & $\varangle 4 B$ & NS5 & 3'UTR \\
\hline
\end{tabular}

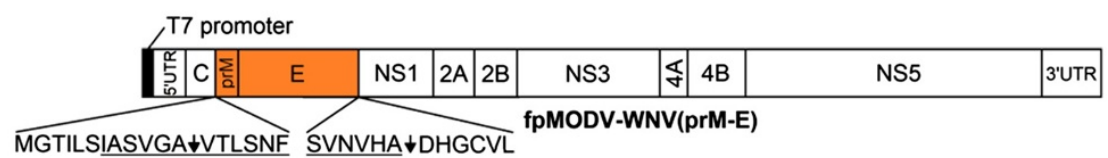

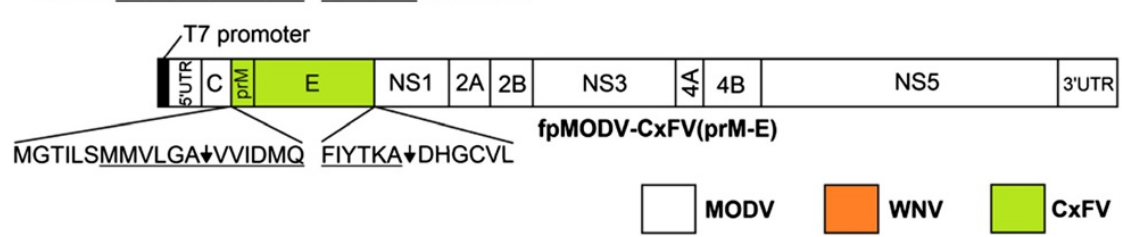

Figure 1 (See legend on next page.) 
(See figure on previous page.)

Figure 1 Schematic of the fusion-PCR strategy used to generate viral chimeras. (A). Strategy used to generate fpMODV-WNV(prM-E) in seven steps. The approximate location of primers and intermediate PCR products are shown on each viral genome (not scaled). Note that just viral sequences are depicted, the actual MODV template was PACNR-FLMODV while WNV template was viral cDNA (see materials and methods). All intermediate products and primers are further described in accompanying Table 1. Chimeric primers are represented by bicolor arrows. Steps 1-4: Products MW1, MW2, MW3 and M4 were generated by PCR with the indicated primers. These fragments were used as construction blocks in subsequent steps in fusion PCRs. Step 5: Products MW1 and MW2 were fused amplifying with primers M-F1 and MW-R2 to generate product MW5. Step 6: MW5 was fused with MW3 using primers M-F1 and M-R3 to give MW6. Step 7: In the final reaction, a full-length chimeric product was generated by fusing MW6 to M4 using primers T7-MOD-F and M-R10600. (B). Maps of final constructs highlighting the resulting amino acid chimeric sequences. Arrows indicate protease cleavage sites. Sequences from the heterologous viruses (WNV or CxFV) are underlined.

(Table 2). All full-length products were purified by phenol/ chloroform extraction and ethanol precipitation, and sequenced across the junctions using overlapping primers for junction verification.

\section{Transfections and virus recovery}

Full-length PCR products (chimeras and full-length MODV) were transfected directly into BSR-T7/5 cells (which stably express T7 RNA polymerase) in order to avoid the in vitro transcription step. BSR-T7/5 cells were seeded into $60 \mathrm{~mm}^{2}$ sterile plates and incubated until there were approximately $9.5 \times 10^{5}$ cells per plate. Cells were transfected with $5 \mu \mathrm{g}$ of purified full-length flavivirus cDNA mixed with $500 \mu \mathrm{l}$ of serum-free Opti-MEM (Invitrogen) and $15 \mu \mathrm{l}$ of TransIT-LT1 transfection reagent (Mirus Bio, Wisconsin) according to the manufacturer's instructions. For those constructs that failed to generate virus, at least three independent transfections were performed and the full-length MODV construct was included as a positive control in each experiment.
Transfected BSR-T7/5 cells were incubated for 4 days then aliquots of each supernatant were collected and inoculated onto subconfluent monolayers of Vero, BHK-21 and C6/36 cells. Several more passages were performed in the same cell type or, where specified, an alternate cell type. Cells were monitored daily for cytopathic effect (CPE). Cell monolayers and supernatants were harvested when $50-70 \%$ of the cells exhibited CPE. If CPE was not observed, cells were harvested at 7 to 9 days post-inoculation (p.i.), with the exception of BHK-21 cells which were harvested at 4 days p.i. since all BHK-21 cell cultures (including the negative control cultures) displayed considerable cell death at this time.

\section{Reverse transcription-polymerase chain reaction}

Total RNA was extracted from cell monolayers and supernatants using Trizol Reagent (Invitrogen) and the QIAamp viral RNA mini kit (Qiagen, Valencia, CA), respectively. Complementary DNAs were generated using Superscript III reverse transcriptase (Invitrogen).

Table 2 Primers used during the construction of full-length flavivirus chimeric DNAs

\begin{tabular}{|c|c|c|c|}
\hline Primer & Polarity & Sequence $^{a}$ & Target \\
\hline $\mathrm{M}-\mathrm{F} 1$ & Sense & 5'ACATTTCCCCGAAAAGTGCCACCTGACGTCTCGAC3' & Cloning vector \\
\hline MW-R1 & Antisense & 5'CCTCCTGGTTTCTTAGACATTCCCGCCACAAAAAGTGG3' & WNV/MODV \\
\hline MWi-R1 & Antisense & 5'TAACTGCTCCTACGCTGGCGATTGACAATATGGTTCCCATCATCC3' & WNV/MODV \\
\hline MC-R1 & Antisense & 5'CTTACCGTCGTCCTTTCCCATTCCCGCCACAAAAAGTGG3' & CXFV/MODV \\
\hline MCi-R1 & Antisense & 5'ACGGCGCCCAGCACCATCATTGACAATATGGTTCCCATCATC3' & CXFV/MODV \\
\hline MW-F2 & Sense & 5'CCACTIITGTGGCGGGAATGTCTAAGAAACCAGGAGG3' & MODV/WNV \\
\hline MWi-F2 & Sense & 5'ATGGATGATGGGAACCATATTGTCAATCGCCAGCGTAGGAGCAG3' & MODV/WNV \\
\hline MC-F2 & Sense & 5'CCACाПITGTGGCGGGAATGGGAAAGGACGACGGTAAG3' & MODV/CXFV \\
\hline MCi-F2 & Sense & 5'ATATGGATGATGGGAACCATATTGTCAATGATGGTGCTGGGCGCCGTC3' & MODV/CXFV \\
\hline MW-R2 & Antisense & 5'CAAGGACACAGCCATGATCAGCGTGCACGTTCACGGAG3' & MODV/WNV \\
\hline$M C-R 2$ & Antisense & 5'CATCAAGGACACAGCCATGATCTGCCTTGGTGTAGATAAAGTATCC3' & MODV/CXFV \\
\hline MW-F3 & Sense & 5'CTCCGTGAACGTGCACGCTGATCATGGCTGTGTCCTTG3' & WNV/MODV \\
\hline $\mathrm{MC}-\mathrm{F} 3$ & Sense & 5'GGATACTTTATCTACACCAAGGCAGATCATGGCTGTGTCCTTGATG3' & CXFV/MODV \\
\hline M-R3 & Antisense & 5'TCCATTTGCATTGATGACTGGAGAACCAGATGAACCAGGAGG3' & MODV \\
\hline $\mathrm{M}-\mathrm{F} 4$ & Sense & 5'AGACTCTTATTCTTGGGGTGGG3' & MODV \\
\hline T7MOD-F & Sense & 5'TAATACGACTCACTATAGGAGTTGATCCTGCCAGCGGTG3' & T7/MODV \\
\hline M-R10600 & Antisense & 5'AGCGGAGGTCATATTCATGACCACACAGATTACATG3' & MODV \\
\hline
\end{tabular}

a Heterologous virus sequences are italicized in chimeric primers, T7 promoter sequence is bolded. 
Where specified, RNA templates were treated with deoxyribonuclease I (DNase I; Invitrogen) prior to reverse transcriptions. PCRs were performed using high fidelity Taq polymerase (Invitrogen). MODV, WNV and CxFV-specific primers were designed using published sequences (Genbank Accession No. AJ242984, AF196835 and FJ663034, respectively). PCR products were examined by $0.8-1 \%$ agarose gel electrophoresis, purified using QIAquick spin columns (Qiagen) and sequenced using a 3730x1 DNA sequencer (Applied Biosystems, Foster City, CA).

\section{Preparation of protein lysates}

BHK-21, Vero and C6/36 cell monolayers, approaching confluency in $75 \mathrm{~cm}^{2}$ flasks, were inoculated with parental or chimeric virus at a multiplicity of infection (m.o.i) of 0.1 and incubated for 4 days (BHK-21 cells) or 7 days (Vero and C6/36 cells). Cells were scraped from the surface of the flask, clarified by centrifugation $\left(10,000 \mathrm{~g}, 10 \mathrm{~min}, 4^{\circ} \mathrm{C}\right)$, washed twice with cold phosphate-buffered saline (PBS), resuspended in lysing buffer $[10 \mathrm{mM}$ Tris- $\mathrm{HCl} \mathrm{pH} 7.5$, $150 \mathrm{mM} \mathrm{NaC1}, 5 \mathrm{mM}$ EDTA, 1\% sodium deoxycholate, 1\% Triton X-100, $0.1 \%$ SDS and a cocktail of protease inhibitors (Sigma, St. Louis, MO)] and placed on ice for $15 \mathrm{~min}$. Samples were microfuged at $4^{\circ} \mathrm{C}$ for $15 \mathrm{~min}$ and supernatants collected and stored at $-80^{\circ} \mathrm{C}$.

\section{Western blots}

Protein samples were mixed with an equal volume of reducing sample buffer, heated $\left(95^{\circ} \mathrm{C}\right.$ for $\left.5 \mathrm{~min}\right)$ and resolved on $8-16 \%$ Tris-glycine gels (Invitrogen). Proteins were transferred to $0.45 \mu \mathrm{m}$ nitrocellulose membranes (Invitrogen) following published protocols [29]. Membranes were blocked overnight at $4^{\circ} \mathrm{C}$ in phosphate-buffered saline (PBS, pH 7.2) with 5\% (wt/vol) non-fat dried milk. Membranes were incubated with (i) 1/100 immune ascitic fluid obtained from mice inoculated with MODV (American Type Culture Collection) or a (ii) $1 / 100$ pooled suspension of anti-WNV E protein monoclonal antibodies 3.67G and 3.91D (Millipore, Billerica, MA) for $1 \mathrm{hr}$ at room temperature. Membranes were then washed and incubated with 1/2000 horseradish peroxidase-conjugated anti-mouse IgG antibody (Invitrogen) for $1 \mathrm{hr}$ at room temperature. Specifically bound antibody was visualized using 3,3'-diaminobenzidine $(0.05 \%$ in PBS with $0.018 \% \mathrm{H}_{2} \mathrm{O}_{2}$ ).

\section{Plaque assays}

Viruses were subjected to serial tenfold dilutions, inoculated onto confluent monolayers of Vero cells in 35-mm culture dishes then incubated at $37^{\circ} \mathrm{C}$ for $60 \mathrm{~min}$. Three milliliters of neutral red-deficient minimum essential medium (Invitrogen) supplemented with 2\% FBS, antibiotics and $1 \%$ agar were added to each well. Plates were incubated at $37^{\circ} \mathrm{C}$ for 3,5 or 7 days for $\mathrm{WNV}$, chimeric virus and
MODV plaque assays, respectively. Another $3 \mathrm{ml}$ of the same medium containing $0.22 \%$ neutral red was then added to each well, and plaques were counted $24 \mathrm{~h}$ later. Viral titers were expressed as plaque-forming units per milliliter (pfu/ml).

\section{Plaque morphology comparisons}

Viruses were inoculated onto confluent monolayers of Vero cells in 35-mm culture dishes then incubated at $37^{\circ} \mathrm{C}$ for $60 \mathrm{~min}$. Three milliliters of neutral red-deficient minimum essential medium (Invitrogen) supplemented with $2 \%$ FBS, antibiotics and $1 \%$ agar were added to each well, and plates were incubated at $37^{\circ} \mathrm{C}$ for 3,5 or 7 days. To fix the cells, $2 \mathrm{ml}$ of $10 \%$ formaldehyde was added directly onto each agar overlay and the plates were incubated at $37^{\circ} \mathrm{C}$ for $60 \mathrm{~min}$. Agar overlays were gently removed, and $0.5 \mathrm{ml}$ of $0.25 \%$ crystal violet $(\mathrm{w} / \mathrm{v})$ in $20 \%$ methanol was added to each well. Once the desired intensity was reached, plates were rinsed several times with tap water and photographed.

\section{Growth curve comparisons}

Subconfluent monolayers of Vero cells in $150 \mathrm{~cm}^{2}$ flasks were inoculated with chimeric virus, MODV or WNV at a m.o.i. of 0.1 Supernatants were collected daily for 7 days, clarified by centrifugation $\left(10,000 \mathrm{~g}, 10 \mathrm{~min}, 4^{\circ} \mathrm{C}\right)$ and stored in aliquots at $-80^{\circ} \mathrm{C}$ until titrated by plaque assay. Three independent experiments were performed. Within each experiment, six replicates of each virus/ dilution/timepoint were tested. Data were used to calculate mean viral titers \pm 1 standard deviation.

\section{Results}

We initially attempted to create chimeric viruses by replacing the C-prM-E and prM-E genes of the MODV infectious cDNA clone with the corresponding sequences of WNV and CxFV using restriction enzyme digestion and direct cloning strategies (data not shown). More than 2,000 bacterial colonies were screened by PCR but none contained full-length C-prM-E or prM-E sequences from the heterologous virus. Approximately 10\% of the colonies contained WNV or CxFV sequences that had been truncated or contained transposon insertions. These findings led us to speculate that the structural genes of WNV and CxFV are toxic to E. coli cells. In order to overcome this problem, the use of bacteria and traditional cloning was replaced by a fusion PCR-based strategy coupled to an in vitro transcription-free system for virus production. Similar methodologies have been developed for other arboviruses [30,31].

Four full-length chimeric flavivirus fusion products, designated fpMODV-WNV(C-prM-E), fpMODV-WNV (prM-E), fpMODV-CxFV(C-prM-E) and fpMODV-CxFV (prM-E), were generated by substituting the C-prM-E and 
prM-E genes of MODV with the corresponding regions of WNV and CxFV. The strategy used to generate fpMODV-WNV(prM-E) is shown in Figure 1, and a similar approach was used to create the three other full-length fusion products. Full-length constructs were transfected into BSR-T7/5 cells. Since all of the full-length products contain a T7 promoter at the 5' end and because BSR-T7/5 cells constitutively express T7 RNA polymerase [27], there was no need to perform an in vitro transcription before the transfection. At 4 days post-transfection, aliquots of each supernatant were collected and inoculated onto Vero, BHK-21 and C6/36 cells. Supernatants were harvested from these cell cultures at 4 days p.i. (BHK-21 cells) or 7 to 9 days p.i. (Vero and C6/36 cells) then passed several more times in the same cell type (or, where specified, a different cell type). Cell monolayers and supernatants were harvested and tested for evidence of virus infection by RT-PCR, Western blot and plaque assay.

Chimeric virus was successfully generated in BSR-T7/5 cells transfected with fpMODV-WNV(prM-E). None of the other full-length chimeric flavivirus fusion products produced detectable virus under these conditions. The chimeric virus, designated MODV-WNV(prM-E), possessed the capacity to infect and replicate within vertebrate but not mosquito cells (Figures 2 and 3). Supernatants harvested from MODV-WNV(prM-E)infected Vero and BHK-21 cells produced distinct

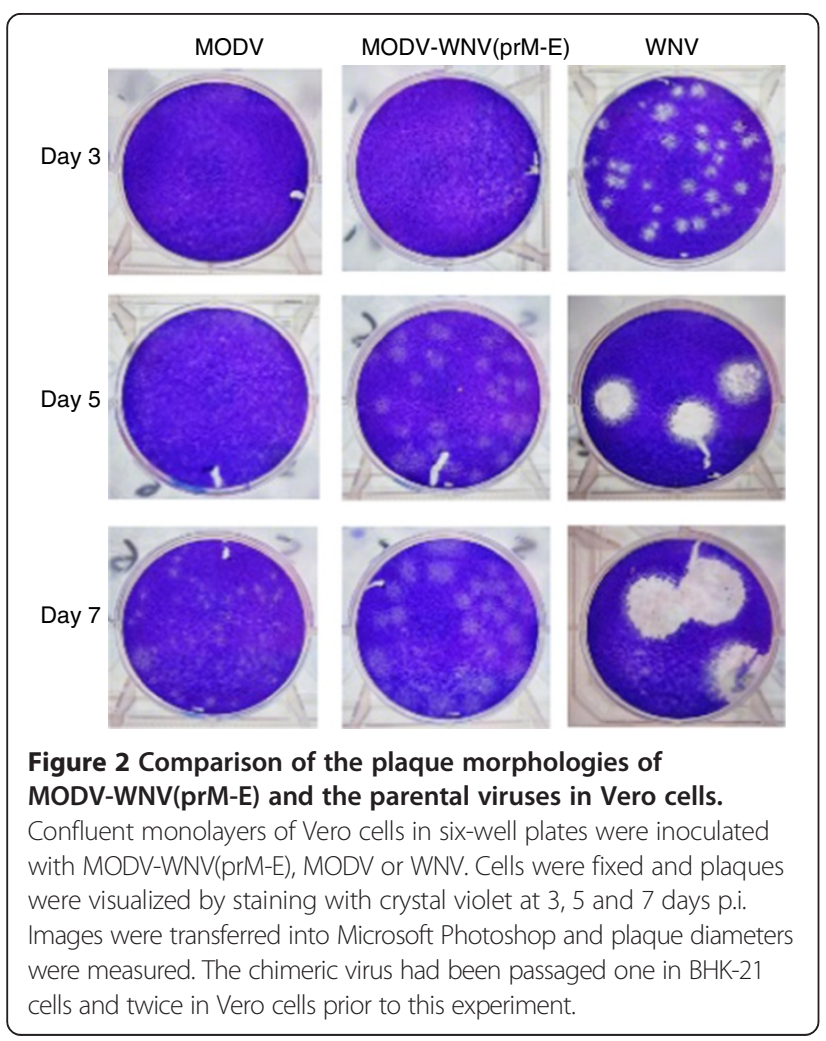

plaques in Vero cells (Figure 2) whereas supernatants harvested from C6/36 cells inoculated with the chimeric virus did not (data not shown). MODV-WNV(prM-E) plaques were larger and could be visualized earlier than MODV plaques but were smaller and visualized later than WNV plaques. At 3 days p.i., MODV and MODV-WNV (prM-E) plaques were barely visible (and too small to be measured accurately) whereas WNV plaques had a mean diameter \pm 1 standard deviation of $1.9 \pm 0.15 \mathrm{~mm}$. At 5 days p.i., MODV, MODV-WNV(prM-E) and WNV plaques were $0.1 \pm 0.02,1.8 \pm 0.14$ and $7.5 \pm 0.46 \mathrm{~mm}$ in diameter, respectively. At 7 days p.i., MODV, MODV-WNV (prM-E) and WNV plaques were $0.9 \pm 0.11,2.9 \pm 0.20$ and $11.7 \pm 0.85 \mathrm{~mm}$ in diameter, respectively. Analyses of variance (ANOVA) F-test showed significant difference among the plaque sizes of the three viruses on both day 5 $(\mathrm{F}=5833.24, \mathrm{DF}=2,87, \mathrm{p}$-value $<0.0001)$ and day 7 $(\mathrm{F}=3705.42, \mathrm{DF}=2,67, \mathrm{p}$-value $<0.0001)$. Post-hoc Tukey's t-test showed that all pairwise comparisons were significant (adjusted p-value <0.0001).

Chimeric flavivirus RNA was detected by RT-PCR in supernatants harvested from Vero and BHK-21 cells, but not C6/36 cells, that had been inoculated with MODV-WNV(prM-E) (data not shown). Nucleotide sequencing of the RT-PCR products confirmed these findings. WNV antigen was detected in cell lysates harvested from MODV-WNV(prM-E)-inoculated Vero cells, but not C6/36 cells, in Western blots performed using WNV-specific monoclonal antibodies (Figure 3). MODV antigen was not detected by Western blot in any cells inoculated with chimeric virus or MODV (both fusionPCR-derived and wild-type MODV) when commercial immune ascitic fluid obtained from mice infected with MODV was used, possibly because the mice failed to generate a sufficient immune response.

It is interesting to note that the chimeric virus did not always produce CPE in Vero cells. CPE was not observed in Vero cells directly inoculated with supernatants harvested from fpMODV-WNV(prM-E)-transfected BSR-T7 cells. An additional passage in Vero cells also failed to result in CPE despite the detection of chimeric viral RNA in these cultures by RT-PCR. However, after a third passage in Vero cells, CPE was clearly observed. In contrast, CPE was observed after one passage in Vero cells when the chimeric virus first underwent one passage in BHK-21 cells (Figure 4).

We sequenced the complete C-prM-E genes of chimeric virus before and after it had been subjected to multiple cell culture passages to assess the genetic stability of the virus as well as to determine whether the acquisition of mutations within the structural genes could explain why some virus stocks possessed the ability to cause CPE in Vero cells while others did not. First, the entire C-prM-E region of MODV-WNV(prM-E) harvested from transfected 

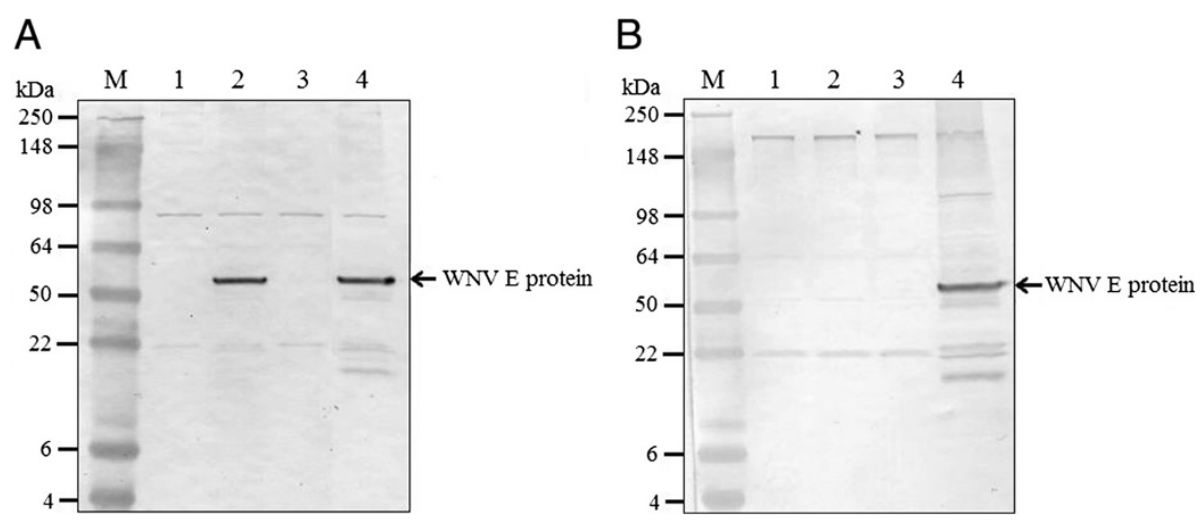

Figure 3 Western blot analysis reveals the presence of WNV antigen in Vero cells, but not C6/36 cells, inoculated with MODV-WNV (prM-E). Lysates were prepared from (A) Vero and (B) C6/36 cells that had been mock-inoculated (lane 1) or inoculated with chimeric virus (lane 2), MODV (lane 3) or WNV (lane 4) at a m.o.i. of 0.1. Lysates were harvested at 7 days p.i. and equal amounts of protein were resolved on 8-16\% Tris-glycine gels and immunoblotted using a pooled suspension of anti-WNV E protein monoclonal antibodies. M denotes the SDS PAGE low-range molecular weight standards (Invitrogen). The arrow shows the expected migration position of the WNV E protein (molecular weight: $53 \mathrm{KDa}$ ).

BSR-T7/5 cell cultures were sequenced, and shown to contain one transition (coordinate 1457) resulting in a conservative substitution when compared to the corresponding region of the parental WNV (Table 3). We also sequenced the C-prM-E genes of chimeric virus that had undergone one passage in BHK-21 cells followed by two passages in Vero cells. Three additional transitions were identified; two mutations were silent and the other was conservative. In addition, we sequenced the $\mathrm{C}$-prM-E region of chimeric virus that had undergone three passages in Vero cells and identified the change in nucleotide coordinate 1457 and four extra substitutions. One mutation was silent, one conservative and two were non-conservative.

MODV-WNV(prM-E) and MODV demonstrated similar replication kinetics and yields in Vero cells while WNV replicated faster and produced a higher peak titer (Figure 5). The chimeric virus and MODV reached mean peak titers of $7( \pm 0.06) \log _{10} \mathrm{pfu} / \mathrm{ml}$ at 5 days p.i. and $6.7( \pm 0.05) \log _{10}$ $\mathrm{pfu} / \mathrm{ml}$ at 4 days p.i., respectively. In contrast, the mean peak titer for WNV was 22 to 48 -fold higher and occurred 2 to 3 days earlier.

\section{Discussion}

Most chimeric flaviviruses have been developed for vaccine purposes. In these studies, live-attenuated vaccine candidates were created by inserting specific genetic elements (typically the prM-E genes) of the flavivirus of interest into a full-length infectious cDNA backbone of another flavivirus such as the YFV vaccine vector, YFV-17D, or an attenuated strain of DENV [32-38]. The construction and characterization of chimeric flaviviruses has also provided critical information on the genetic elements that modulate the differential vector ranges, transmissibilities and disease phenotypes of divergent flaviviruses. Several of these studies have been performed using representative flaviviruses from the tick-borne and mosquito-borne groups [39-44]. More pertinent to this investigation are the few studies that describe the construction and characterization of viral chimeras between NKV and arthropod/vertebrate flaviviruses [45-47]. Five chimeric flaviviruses have now been created between viruses from these two groups. The first chimeric virus was generated by substituting the prM-E genes of an infectious YFV cDNA infectious clone with the homologous genes of MODV [46] and the second

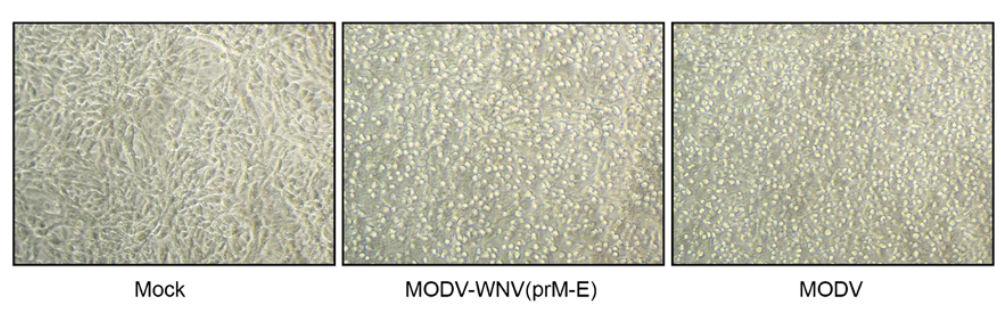

Figure 4 Detection of cytopathic effect in Vero cells inoculated with MODV-WNV(prM-E). MODV-WNV(prM-E) and MODV that had been passaged twice in Vero cells were inoculated onto fresh monolayers of Vero cells that were monitored for 5 or 8 days, respectively. Mock-infected Vero cells that were incubated for 5 days were also included. Magnification $=100 x$. 
Table 3 Mutations accrued in the C-prM-E genes of MODV-WNV(prM-E) during transfection and passage in designated cell types

\begin{tabular}{|c|c|c|c|c|}
\hline Passage history & Nucleotide position & Amino acid position & Nucleotide change & Amino acid change \\
\hline Original Inoculum (BSR-T7) & 1457 & E-167 & $C \rightarrow T$ & Leu $\rightarrow$ Phe \\
\hline \multirow[t]{4}{*}{ BHK-21 + Vero + Vero } & 323 & $C-72$ & $\mathrm{~T} \rightarrow \mathrm{C}$ & Silent \\
\hline & 1457 & $E-167$ & $C \rightarrow T$ & Leu $\rightarrow$ Phe \\
\hline & 1771 & $E-271$ & $\mathrm{~T} \rightarrow \mathrm{C}$ & Silent \\
\hline & 2372 & $\mathrm{E}-472$ & $A \rightarrow G$ & Met $\rightarrow$ Val \\
\hline \multirow[t]{5}{*}{ Vero + Vero + Vero } & 462 & prM-2 & $C \rightarrow T$ & Thr $\rightarrow$ lle \\
\hline & 1307 & $\mathrm{E}-117$ & $\mathrm{G} \rightarrow \mathrm{A}$ & $\mathrm{Ala} \rightarrow \mathrm{Thr}$ \\
\hline & 1457 & E-167 & $C \rightarrow T$ & Leu $\rightarrow$ Phe \\
\hline & 1894 & $\mathrm{E}-216$ & $\mathrm{~T} \rightarrow \mathrm{C}$ & Silent \\
\hline & 2261 & E-435 & $\mathrm{T} \rightarrow \mathrm{C}$ & Phe $\rightarrow$ Leu \\
\hline
\end{tabular}

contains the prM-E genes of MODV in a DENV-2 backbone [45]. Both chimeric viruses replicated in C6/36 cells indicating that the inability of NKV flaviviruses to infect mosquito cells is not mediated by the viral envelope but by a post-entry event. Two more chimeric viruses were constructed by replacing the conserved pentanucleotide sequence (CPS) or variable region (VR) of the 3' UTR of a DENV-4 infectious clone with the corresponding region of MODV. Both viruses could infect C6/36 cells and adult mosquitoes at similar efficiencies to DENV-4 suggesting that the CPS and VR of mosquito/ vertebrate flaviviruses are not required for mosquito infectivity. We too have successfully created a chimeric virus using a NKV and mosquito-borne flavivirus but, unlike the above studies, our virus was constructed using the vertebrate-specific virus as the backbone. The virus, designated MODV-WNV(prM-E), was created

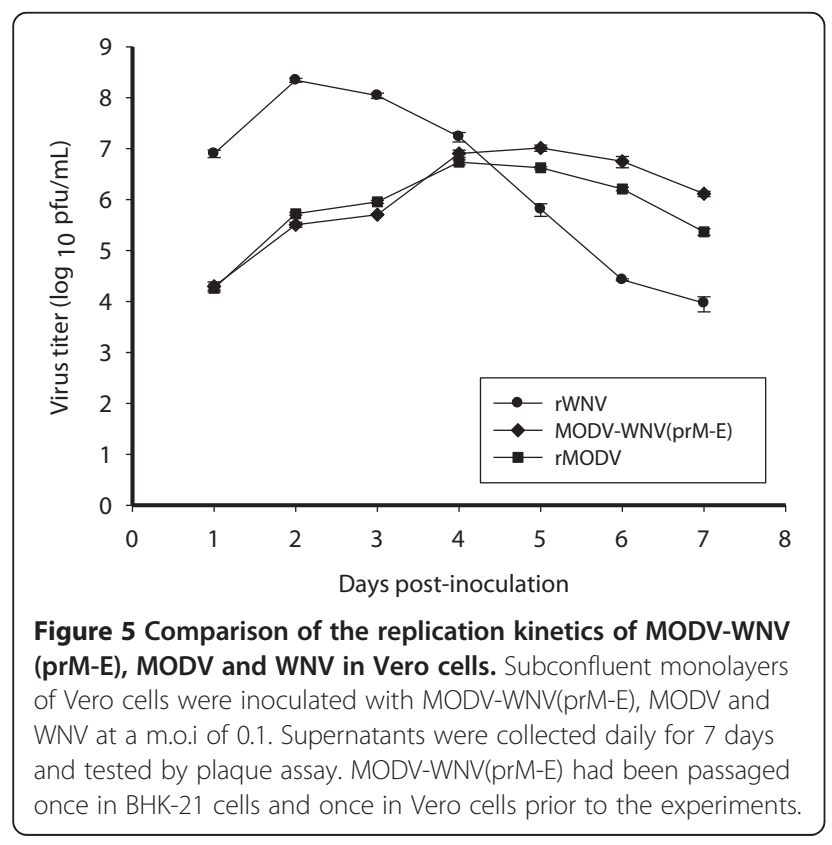

by replacing the prM-E genes of a MODV infectious clone with the corresponding sequences of WNV. MODV-WNV (prM-E) possesses the capacity to infect and replicate within vertebrate but not mosquito cell cultures indicating that there are sequence elements outside of the prM-E region that dictate the vertebrate-specific host range of MODV. However, it is important to note that the mosquito cells were cultured at a much lower temperature than the mammalian cells and thus, it is not known whether MODV-WNV(prM-E) was unable to infect mosquito cells due to a cell tropism restriction or a temperaturedependent restriction.

The fusion product designated fpMODV-CxFV(prM-E), which was created by replacing the prM and $\mathrm{E}$ genes of MODV with the homologous sequences of $\mathrm{CxFV}$, failed to yield detectable virus. This finding is in contrast to the numerous studies that report the successful production of chimeric virus after the prM-E genes of one flavivirus are replaced with those of another [42,48-54]. However, all of these studies were performed with flaviviruses that possess at least one common host. Indeed, although chimeric viruses have been created between viruses as divergent as tick- and mosquito-borne flaviviruses, and NKV and mosquito-borne flaviviruses, all viruses within these groups possess the ability to replicate within vertebrate cells. In contrast, ISFs and NKV flaviviruses do not possess a common host by virtue of their insect and vertebratespecific phenotypes. Thus, the generation of chimeric viruses between ISFs and NKV flaviviruses may not be achievable or, at the very least, will prove extremely challenging because their genomes and resulting translation products may be fundamentally incompatible as a consequence of their evolutionary divergence and specialization to vastly different hosts.

Conserved complementary cyclization sequences reside within the capsid gene and 3' UTR of the flavivirus genome. These sequences interact with one another to facilitate genome cyclization and are essential for viral replication 
$[55,56]$. Thus, one explanation for the inability to produce infectious virus with the fusion products containing the C-prM-E genes of WNV and CxFV is because the genome cyclization elements within the 3' UTR of MODV and the $\mathrm{C}$ gene of the alternate virus do not have sufficient complementary to support genome cyclization. In this regard, replacement of the 3'UTR of a DENV-4 infectious clone with the corresponding region of MODV also failed to produce virus [47]. Virus was also unable to be recovered when both UTRs as well as the $C$ gene of DENV-4 were replaced with the corresponding regions of either LGTV or MODV, despite the presence of complementary cyclization sequences $[44,47]$. The authors speculated that infectious virus was not produced because fundamental incompatibilities exist between the UTRs and replication complexes of highly divergent (e.g. mosquito-borne, tick-borne and vertebrate-specific) flaviviruses. However, C-prM-E gene substitutions between divergent flaviviruses have occasionally proven successful; Pletnev and colleagues produced chimeric virus after replacing all three structural genes of DENV-4 with those of TBEV [41].

The inability to produce chimeric virus with fpMODVCxFV(prM-E), fpMODV-CxFV(C-prM-E) and fpMODV$\mathrm{WNV}(\mathrm{C}-\mathrm{prM}-\mathrm{E})$ is unlikely due to aberrant replication complex formation. Assembly of the viral replication complex should not have been impeded due to mismatches between the various viral and cellular proteins that interact during this process because no nonstructural gene substitutions were made. It is also unlikely that correct proteolytic processing of the chimeric polyproteins could not occur. Amino acid sequence alignments have shown that the predicted cleavage sites required for proteolytic cleavage of the CxFV and MODV polyproteins are similar to one another and to those of WNV and other dual-host flaviviruses [22,57-59]. Although the junctions of all four constructs were sequenced and shown to contain no nucleotide errors, these constructs were not sequenced in their entirety and thus, we cannot dismiss the possibility that the non-viable constructs contained lethal mutations outside the junctions that occurred during one of the PCR amplifications. Another explanation why fpMODV-CxFV(C-prM-E) and fpMODV-WNV(C-prM-E) failed to produce virus is because the encapsidation signal sequence of MODV (which, as with all flaviviruses, remains to be identified [60]) is not recognized by the capsid proteins of WNV or $\mathrm{CxFV}$.

The replication kinetics and yields of MODV-WNV (prM-E) in Vero cells were similar to those of MODV. These data suggest that genetic elements outside of the prM-E region dictate the in vitro replication profiles of NKV flaviviruses in vertebrate cells. Other studies have also shown that chimeric flaviviruses generated by prM-E gene substitutions exhibit replication kinetics and yields similar to the virus from which the nonstructural genes were derived but distinct from the virus that contributed the prM-E sequences $[46,51,61]$. For instance, the in vitro replication kinetics of a chimeric virus that possessed the prM-E genes of MODV in a YFV-17D backbone were similar to those of YFV-17D but distinct from MODV which reached a higher peak titer [46]. Although the chimeric virus and MODV displayed similar in vitro replication kinetics, these two viruses exhibited differential plaque morphologies in Vero cells. MODV-WNV(prM-E) plaques were at least threefold larger than MODV plaques but approximately fourfold smaller than WNV plaques. These findings indicate that genetic elements both within and outside of the prM-E region modulate the plaque sizes of NKV flaviviruses. These findings differ from most other studies which compare the plaque sizes of chimeric flaviviruses generated by prM-E gene substitutions to those of both parental viruses. Usually prM-E gene substitutions generate chimeric viruses that produce plaques that are indistinguishable from one of the parental viruses [51,62-64] or are smaller than both parental viruses $[46,65,66]$. However, replacement of the prM-E genes of JEV with those of DENV-4 produced a chimeric virus which, like our chimeric virus, exhibited an intermediate plaque phenotype; the chimeric virus produced plaques that were smaller than JEV but larger than DENV-4 in mammalian cells [67].

MODV-WNV(prM-E) did not always cause CPE in Vero cells, and the occurrence of CPE appeared dependent on the passage history of the virus. MODV-WNV(prM-E) was able to induce CPE after a single passage in Vero cells if it had first been cultured in BHK-21 cells. In contrast, CPE did not occur in Vero cells until the third passage when the virus had not been passaged in BHK-21 cells. One explanation for these findings is that MODV-WNV(prM-E) replicates more efficiently in BHK-21 cells as compared to Vero cells, possibly because it is a rodent cell line and most of the chimeric flaviviral genome was acquired from a virus with a natural host range that is apparently restricted to rodents. Alternatively, repeated passaging of the virus in Vero cells could have resulted in the accumulation of mutations that altered its ability to induce CPE in this cell type. In this regard, the C-prM-E gene sequence of chimeric virus derived from the original inoculum contained one nonsynonymous mutation when compared to the corresponding regions of parental viruses while chimeric viruses that had undergone three passages in BHK-21 and/or Vero cells acquired three to four additional mutations in the structural gene region. Whether these mutations, or mutations that may have occurred elsewhere in the viral genome, altered the ability of the virus to induce CPE is not known but it does offer a likely explanation.

In summary, we report the first chimeric flavivirus to be constructed using a NKV flavivirus as the backbone. 
We also report the first attempts to create a chimeric flavivirus between an ISF and NKV flavivirus. Two constructs were generated, including one that contains the CxFV prM-E genes in a MODV backbone, but neither yielded detectable virus. Most success in the generation of chimeric flaviviruses has been achieved through prM-E gene substitutions. However, unlike our study, all previous studies were performed using flaviviruses that share a common host. These findings indicate that the successful generation of chimeric viruses between ISFs and NKV flaviviruses will prove extremely challenging due to the evolutionary divergence and differential host ranges of these viruses.

\section{Competing interests}

The authors declare that they have no competing interests.

\section{Authors' contributions}

RS constructed and characterized the chimeras and drafted the manuscript $\mathrm{JCT}$ assisted in the construction and characterization of the chimeras and helped to draft the manuscript. WAM participated in the design and coordination of the study. PJB participated in the design and coordination of the study. BJB conceived of the study, and participated in its design and coordination and helped to draft the manuscript. All authors read and approved the final manuscript.

\section{Acknowledgments}

This study was supported by the lowa State University Plant Sciences Institute Virus-Insect Interactions Initiative. The authors thank Charlie Bahnson, Matthew Meyers, Dr. Cathy Miller, Kate Carroll, Dr. Guo Baoging, Jill Gander, Dr. Mark Mogler and Dr. Dustin Loy for technical assistance and advice. The authors also thank Chong Wang for performing the statistical analysis and Kim Adams for photographing virus plaques.

\section{Author details}

'Department of Veterinary Microbiology and Preventive Medicine, College of Veterinary Medicine, lowa State University, Ames, lowa, USA. ${ }^{2}$ Department of Plant Pathology and Microbiology, College of Agriculture and Life Sciences, lowa State University, Ames, lowa, USA. ${ }^{3}$ Department of Medical Microbiology, Leiden University Medical Center, NL-2300, RC, Leiden, The Netherlands.

Received: 4 April 2014 Accepted: 19 August 2014 Published: 24 August 2014

\section{References}

1. Lindenbach BD, Thiel H-J, Rice CM: Flaviviridae: the viruses and their replication. In Fields Virology. Fifthth edition. Edited by Knipe DM, Howley PM. Philadelphia PA: Lippincott Williams and Wilkins; 2007:1101-1152

2. Markoff $L: 5^{\prime}-$ and $3^{\prime}$-noncoding regions in flavivirus RNA. Adv Virus Res 2003, 59:177-228.

3. Rice CM, Lenches EM, Eddy SR, Shin SJ, Sheets RL, Strauss JH: Nucleotide sequence of yellow fever virus: implications for flavivirus gene expression and evolution. Science 1985, 229:726-733.

4. Falgout $B$, Pethel $M$, Zhang YM, Lai $C J$ : Both nonstructural proteins NS2B and NS3 are required for the proteolytic processing of dengue virus nonstructural proteins. J Virol 1991, 65:2467-2475.

5. Stadler K, Allison SL, Schalich J, Heinz FX: Proteolytic activation of tick-borne encephalitis virus by furin. J Virol 1997, 71:8475-8481.

6. Chen Y, Maguire T, Marks RM: Demonstration of binding of dengue virus envelope protein to target cells. J Virol 1996, 70:8765-8772.

7. Guirakhoo F, Bolin RA, Roehrig JT: The Murray Valley encephalitis virus prM protein confers acid resistance to virus particles and alters the expression of epitopes within the R2 domain of E glycoprotein. Virology 1992, 191:921-931.

8. Heinz FX, Stiasny K, Puschner-Auer G, Holzmann H, Allison SL, Mandl CW, Kunz C: Structural changes and functional control of the tick-borne encephalitis virus glycoprotein $\mathrm{E}$ by the heterodimeric association with protein prM. Virology 1994, 198:109-117.

9. Rey FA, Heinz FX, Mandl C, Kunz C, Harrison SC: The envelope glycoprotein from tick-borne encephalitis virus at 2 A resolution. Nature 1995, 375:291-298.

10. Egloff MP, Benarroch D, Selisko B, Romette JL, Canard B: An RNA cap (nucleoside-2'-O-)-methyltransferase in the flavivirus RNA polymerase NS5: crystal structure and functional characterization. EMBO J 2002, 21:2757-2768.

11. Tan BH, Fu J, Sugrue RJ, Yap EH, Chan YC, Tan YH: Recombinant dengue type 1 virus NS5 protein expressed in Escherichia coli exhibits RNA-dependent RNA polymerase activity. Virology 1996, 216:317-325.

12. Cook S, Moureau G, Kitchen A, Gould EA, de Lamballerie X, Holmes EC, Harbach RE: Molecular evolution of the insect-specific flaviviruses. J Gen Virol 2012, 93:223-234.

13. Kuno G: Host range specificity of flaviviruses: correlation with in vitro replication. J Med Entomol 2007, 44:93-101.

14. Gubler DJ, Kuno G, Markoff L: Flaviviruses. In Fields Virology. Fifthth edition. Edited by Knipe DM, Howley PM. Philadelphia PA: Lippincott Williams and Wilkins; 2007:1153-1252.

15. Burns KF, Farinacci CJ: Virus of bats antigenically related to St. Louis encephalitis. Science 1956, 123:227.

16. Johnson HN: Ecological implications of antigenically related mammalian viruses for which arthropod vectors are unknown and avian associated soft tick viruses. Jpn J Med Sci Biol 1967, 20(Suppl):160-166.

17. Bell JF, Thomas LA: A New Virus, "Mml", Enzootic in Bats (Myotis Lucifugus) of Montana. Am J Trop Med Hyg 1964, 13:607-612.

18. Constantine DG, Woodall DF: Latent Infection of Rio Bravo Virus in Salivary Glands of Bats. Public Health Rep 1964, 79:1033-1039.

19. Zarnke RL, Yuill TM: Modoc-like virus isolated from wild deer mice (Peromyscus maniculatus) in Alberta. J Wild Dis 1985, 21:94-99.

20. Crabtree MB, Sang RC, Stollar V, Dunster LM, Miller BR: Genetic and phenotypic characterization of the newly described insect flavivirus, Kamiti River virus. Arch Virol 2003, 148:1095-1118.

21. Haddow AD, Guzman H, Popov VL, Wood TG, Widen SG, Haddow AD, Tesh RB, Weaver SC: First isolation of Aedes flavivirus in the Western Hemisphere and evidence of vertical transmission in the mosquito Aedes (Stegomyia) albopictus (Diptera: Culicidae). Virology 2013, 440:134-139.

22. Hoshino K, Isawa H, Tsuda Y, Yano K, Sasaki T, Yuda M, Takasaki T, Kobayashi M, Sawabe K: Genetic characterization of a new insect flavivirus isolated from Culex pipiens mosquito in Japan. Virology 2007, 359:405-414.

23. Stollar V, Thomas VL: An agent in the Aedes aegypti cell line (Peleg) which causes fusion of Aedes albopictus cells. Virology 1975, 64:367-377.

24. Saiyasombat R, Bolling BG, Brault AC, Bartholomay LC, Blitvich BJ: Evidence of efficient transovarial transmission of Culex flavivirus by Culex pipiens (Diptera: Culicidae). J Med Entomol 2011, 48:1031-1038.

25. Gould EA, de Lamballerie X, Zanotto PM, Holmes EC: Origins, evolution, and vector/host coadaptations within the genus Flavivirus. Adv Virus Res 2003, 59:277-314.

26. Kuno G, Chang GJ, Tsuchiya KR, Karabatsos N, Cropp CB: Phylogeny of the genus Flavivirus. J Virol 1998, 72:73-83.

27. Buchholz UJ, Finke S, Conzelmann K-K: Generation of Bovine Respiratory Syncytial Virus (BRSV) from cDNA: BRSV NS2 Is Not Essential for Virus Replication in Tissue Culture, and the Human RSV Leader Region Acts as a Functional BRSV Genome Promoter. J Virol 1999, 73:251-259.

28. Blitvich B, Lin M, Dorman KS, Soto V, Hovav E, Tucker BJ, Staley M, Platt KB, Bartholomay LC: Genomic sequence and phylogenetic analysis of Culex flavivirus, an insect-specific flavivirus, isolated from Culex pipiens in lowa (Diptera: Culicidae). J Med Entomol 2009, 48:1031-1038.

29. Towbin H, Staehelin T, Gordon J: Electrophoretic transfer of proteins from polyacrylamide gels to nitrocellulose sheets: procedure and some applications. Proc Natl Acad Sci U S A 1979, 76:4350-4354.

30. Edmonds J, van Grinsven E, Prow N, Bosco-Lauth A, Brault AC, Bowen RA, Hall RA, Khromykh AA: A novel bacterium-free method for generation of flavivirus infectious DNA by circular polymerase extension reaction allows accurate recapitulation of viral heterogeneity. J Virol 2013, 87:2367-2372.

31. Kohl A, Hart TJ, Noonan C, Royall E, Roberts LO, Elliott RM: A bunyamwera virus minireplicon system in mosquito cells. J Virol 2004, 78:5679-5685.

32. Blaney JE Jr, Speicher J, Hanson CT, Sathe NS, Whitehead SS, Murphy BR, Pletnev AG: Evaluation of St. Louis encephalitis virus/dengue virus type 4 antigenic chimeric viruses in mice and rhesus monkeys. Vaccine 2008, 26:4150-4159 
33. Chambers TJ, Nestorowicz A, Mason PW, Rice CM: Yellow fever/Japanese encephalitis chimeric viruses: construction and biological properties. J Virol 1999, 73:3095-3101.

34. Durbin AP, Wright PF, Cox A, Kagucia W, Elwood D, Henderson S, Wanionek K, Speicher J, Whitehead SS, Pletnev AG: The live attenuated chimeric vaccine rWN/DEN4Delta30 is well-tolerated and immunogenic in healthy flavivirus-naive adult volunteers. Vaccine 2013, 31:5772-5777.

35. Guirakhoo F, Weltzin R, Chambers TJ, Zhang ZX, Soike K, Ratterree M, Arroyo J, Georgakopoulos K, Catalan J, Monath TP: Recombinant chimeric yellow fever-dengue type 2 virus is immunogenic and protective in nonhuman primates. J Virol 2000, 74:5477-5485.

36. Guy B, Guirakhoo F, Barban V, Higgs S, Monath TP, Lang J: Preclinical and clinical development of YFV 17D-based chimeric vaccines against dengue West Nile and Japanese encephalitis viruses. Vaccine 2010, 28:632-649.

37. Lai CJ, Monath TP: Chimeric flaviviruses: novel vaccines against dengue fever, tick-borne encephalitis, and Japanese encephalitis. Adv Virus Res 2003, 61:469-509.

38. Wright PF, Ankrah S, Henderson SE, Durbin AP, Speicher J, Whitehead SS, Murphy BR, Pletnev AG: Evaluation of the Langat/dengue 4 chimeric virus as a live attenuated tick-borne encephalitis vaccine for safety and immunogenicity in healthy adult volunteers. Vaccine 2008, 26:882-890.

39. Engel AR, Mitzel DN, Hanson CT, Wolfinbarger JB, Bloom ME, Pletnev AG: Chimeric tick-borne encephalitis/dengue virus is attenuated in Ixodes scapularis ticks and Aedes aegypti mosquitoes. Vector-Borne Zoonotic Dis 2011, 11:665-674.

40. Engel AR, Rumyantsev AA, Maximova OA, Speicher JM, Heiss B, Murphy BR, Pletnev AG: The neurovirulence and neuroinvasiveness of chimeric tick-borne encephalitis/dengue virus can be attenuated by introducing defined mutations into the envelope and NS5 protein genes and the 3 ' non-coding region of the genome. Virology 2010, 405:243-252.

41. Pletnev AG, Bray M, Huggins J, Lai CJ: Construction and characterization of chimeric tick-borne encephalitis/dengue type 4 viruses. Proc Natl Acad SCl US A 1992, 89:10532-10536.

42. Pletnev AG, Bray M, Lai CJ: Chimeric tick-borne encephalitis and dengue type 4 viruses: effects of mutations on neurovirulence in mice. J Virol 1993, 67:4956-4963.

43. Pletnev AG, Men R: Attenuation of the Langat tick-borne flavivirus by chimerization with mosquito-borne flavivirus dengue type 4. Proc Nat Acad Sci U S A 1998, 95:1746-1751.

44. Tumban E, Mitzel DN, Maes NE, Hanson CT, Whitehead SS, Hanley KA: Replacement of the 3' untranslated variable region of mosquito-borne dengue virus with that of tick-borne Langat virus does not alter vector specificity. J Gen Virol 2011, 92:841-848.

45. Charlier N, Davidson A, Dallmeier K, Molenkamp R, De Clercq E, Neyts J: Replication of not-known-vector flaviviruses in mosquito cells is restricted by intracellular host factors rather than by the viral envelope proteins. J Gen Virol 2010, 91:1693-1697.

46. Charlier N, Molenkamp R, Leyssen P, Paeshuyse J, Drosten C, Panning M, De Clercq E, Bredenbeek PJ, Neyts J: Exchanging the yellow fever virus envelope proteins with Modoc virus prM and E proteins results in a chimeric virus that is neuroinvasive in SCID mice. J Virol 2004, 78:7418-7426.

47. Tumban E, Maes NE, Schirtzinger EE, Young Kl, Hanson CT, Whitehead SS, Hanley KA: Replacement of conserved or variable sequences of the mosquito-borne dengue virus 3' UTR with homologous sequences from Modoc virus does not change infectivity for mosquitoes. J Gen Virol 2013, 94:783-788.

48. Arroyo J, Miller C, Catalan J, Myers GA, Ratterree MS, Trent DW, Monath TP: ChimeriVax-West Nile virus live-attenuated vaccine: preclinical evaluation of safety, immunogenicity, and efficacy. J Virol 2004, 78:12497-12507.

49. Butrapet S, Rabablert J, Angsubhakorn S, Wiriyarat W, Huang C, Kinney R, Punyim S, Bhamarapravati N: Chimeric dengue type 2/type 1 viruses induce immune responses in cynomolgus monkeys. Southeast Asian $J$ Trop Med Public Health 2002, 33:589-599.

50. Huang CY, Butrapet S, Tsuchiya KR, Bhamarapravati N, Gubler DJ, Kinney RM: Dengue 2 PDK-53 virus as a chimeric carrier for tetravalent dengue vaccine development. J Virol 2003, 77:11436-11447.

51. Maharaj PD, Anishchenko M, Langevin SA, Fang Y, Reisen WK, Brault AC: Structural gene (prME) chimeras of St Louis encephalitis virus and West Nile virus exhibit altered in vitro cytopathic and growth phenotypes. J Gen Virol 2012, 93:39-49.

52. Pletnev AG, Bray M, Hanley KA, Speicher J, Elkins R: Tick-borne Langat/ mosquito-borne dengue flavivirus chimera, a candidate live attenuated vaccine for protection against disease caused by members of the tick-borne encephalitis virus complex: evaluation in rhesus monkeys and in mosquitoes. J Virol 2001, 75:8259-8267.

53. Pletnev AG, Putnak R, Speicher J, Wagar EJ, Vaughn DW: West Nile virus/dengue type 4 virus chimeras that are reduced in neurovirulence and peripheral virulence without loss of immunogenicity or protective efficacy. Proc Natl Acad Sci U S A 2002, 99:3036-3041.

54. Pugachev KV, Guirakhoo F, Mitchell F, Ocran SW, Parsons M, Johnson BW, Kosoy OL, Lanciotti RS, Roehrig JT, Trent DW, Monath TP: Construction of yellow fever/St. Louis encephalitis chimeric virus and the use of chimeras as a diagnostic tool. Am J Trop Med Hyg 2004, 71:639-645.

55. Khromykh AA, Meka H, Guyatt KJ, Westaway EG: Essential role of cyclization sequences in flavivirus RNA replication. J Virol 2001, 75:6719-6728

56. Kofler RM, Hoenninger VM, Thurner C, Mandl CW: Functional analysis of the tick-borne encephalitis virus cyclization elements indicates major differences between mosquito-borne and tick-borne flaviviruses. J Virol 2006, 80:4099-4113.

57. Castle $E$, Leidner U, Nowak T, Wengler G, Wengler G: Primary structure of the West Nile flavivirus genome region coding for all nonstructural proteins. Virology 1986, 149:10-26.

58. Castle E, Nowak T, Leidner U, Wengler G, Wengler G: Sequence analysis of the viral core protein and the membrane-associated proteins $\mathrm{V} 1$ and NV2 of the flavivirus West Nile virus and of the genome sequence for these proteins. Virology 1985, 145:227-236.

59. Leyssen P, Charlier N, Lemey P, Billoir F, Vandamme AM, De Clercq E, de Lamballerie $X$, Neyts J: Complete genome sequence, taxonomic assignment, and comparative analysis of the untranslated regions of the Modoc virus, a flavivirus with no known vector. Virology 2002, 293:125-140.

60. Roby JA, Funk A, Khromykh AA: Flavivirus replication and assembly. In Molecular Virology and Control of Flaviviruses. Edited by Shi P-Y. U.K.: Horizon Scientific Press Norfolk; 2012:21-50.

61. Huang CY, Silengo SJ, Whiteman MC, Kinney RM: Chimeric dengue 2 PDK-53/West Nile NY99 viruses retain the phenotypic attenuation markers of the candidate PDK-53 vaccine virus and protect mice against lethal challenge with West Nile virus. J Virol 2005, 79:7300-7310.

62. Caufour PS, Motta MC, Yamamura AM, Vazquez S, Ferreira II, Jabor AV, Bonaldo MC, Freire MS, Galler R: Construction, characterization and immunogenicity of recombinant yellow fever 17D-dengue type 2 viruses. Virus Res 2001, 79:1-14

63. Li XF, Deng YQ, Yang HQ, Zhao $H$, Jiang $T$, Yu XD, Li SH, Ye Q, Zhu SY, Wang HJ, Zhang Y, Ma J, Yu YX, Liu ZY, Li YH, Qin ED, Shi PY, Qin CF: A chimeric dengue virus vaccine using Japanese encephalitis virus vaccine strain SA14-14-2 as backbone is immunogenic and protective against either parental virus in mice and nonhuman primates. J Virol 2013. 87:13694-13705.

64. Prow NA, May FJ, Westlake DJ, Hurrelbrink RJ, Biron RM, Leung JY, McMinn PC, Clark DC, Mackenzie JS, Lobigs M, Khromykh AA, Hall RA: Determinants of attenuation in the envelope protein of the flavivirus Alfuy. J Gen Viro/ 2011, 92:2286-2296.

65. Pletnev AG, Karganova GG, Dzhivanyan TI, Lashkevich VA, Bray M: Chimeric Langat/Dengue viruses protect mice from heterologous challenge with the highly virulent strains of tick-borne encephalitis virus. Virology 2000 274:26-31

66. Wang HJ, Li XF, Ye Q, Li SH, Deng YQ, Zhao H, Xu YP, Ma J, Qin ED, Qin CF: Recombinant chimeric Japanese encephalitis virus/tick-borne encephalitis virus is attenuated and protective in mice. Vaccine 2014, 32:949-956.

67. Mathenge EG, Parquet Mdel C, Funakoshi Y, Houhara S, Wong PF, Ichinose A Hasebe F, Inoue S, Morita K: Fusion PCR generated Japanese encephalitis virus/dengue 4 virus chimera exhibits lack of neuroinvasiveness, attenuated neurovirulence, and a dual-flavi immune response in mice. J Gen Virol 2004, $85: 2503-2513$

doi:10.1186/1743-422X-11-150

Cite this article as: Saiyasombat et al:: Substitution of the premembrane and envelope protein genes of Modoc virus with the homologous sequences of West Nile virus generates a chimeric virus that replicates in vertebrate but not mosquito cells. Virology Journal 2014 11:150. 